\title{
THE FULL CIRCLE: CASE TEACHING AND WRITING IN BUSINESS COURSES
}

\author{
Marina Apaydin, MsEE, MBA, MA, PhD \\ American University of Beirut, Lebanon
}

\begin{abstract}
While including case studies as part of the curriculum is widespread in business education in North America, and to a lesser extent, in Europe; in the emerging economies this instructional approach is still novel. Furthermore, case writing, has been traditionally the realm of the instructors, and sometimes graduate students - even in the most developed educational institutions. In this paper I present a "full-circle" approach to case teaching and writing whereby undergraduate students are involved in all parts of the case experience. The paper presents a specific theoretically grounded methodological framework, and describes the results of its successful implementation at the American University of Cairo and the American University of Beirut during the period 2010-2014. Overall, 17 cases accompanied by teaching notes co-authored by students were published by Ivey Publishing, Pearson, McGraw-Hill and peer reviewed academic journals. Involving students in creating educational materials for their peers has proven to be a novel and rewarding experience for all parties involved.
\end{abstract}

Keywords: Case method, business education

\section{Introduction}

Using cases in business education is not new. Effective case teaching offers students the opportunity to grapple with the complex nature of decision-making in an international environment. Despite being a very significant benefit of using cases in the classroom, it is but one of many. In this paper, I argue that the benefits can be extended significantly beyond learning the content of course material, and beyond the scope of a single course. Taking a long-term (life-cycle) perspective on cases may help not only enhance immediate learning, but also create a closer connection between stakeholders (students, companies, instructors) with synergetic benefits to all parties: 
- Students-writers may enhance their resumes with published works and employment perspectives with the focal companies.

- Students-solvers would feel more affinity with cases written by their peers, and covering their own region.

- Focal companies would receive not only a detailed research on possible countries - targets for expansion, but also an access to the best students willing to extend extra effort.

- Instructors could benefit from better student evaluations (as a result of a more rewarding class), case authorship, collection of material for a qualitative research paper (4 cases is enough according to Yin, 1990) and consulting opportunities with focal companies not to mention the intrinsic satisfaction from seeing the students learn and success.

\section{I.}

\section{Rational for the use of case teaching and writing in business courses ${ }^{1}$}

What I hear, I forget; what I see, I remember; what I do, I understand - Chinese proverb

In a changing environment, the human ability to learn is fundamental for adaptation. Indeed, in the modern world of continuous, rapid change, effective learning and innovation may be the only sustainable competitive advantage (DeGues, 1988). Participative educational methods stimulate both cognitive and behavioral types of learning, leading to a higher level of knowledge and skills acquisition (Inkpen and Crossan, 1995).

The Socratic method of participative learning has been known since antiquity. Almost a century ago, the Harvard Business School chose the case method as an effective way of teaching business. Today cases are taught around the world in a wide variety of disciplines.

"A case is a description of an actual situation, commonly involving a decision, a challenge, an opportunity, a problem or an issue faced by a person, or persons in an organization. A case is based on actual field data, authenticated by a release. It is not an armchair or fictional variety." (Erskine, Leenders \& MauffetteLeenders, 2003: 9).

Although the method is drastically different from the traditional classroom lecture style, it should not be perceived as an "all or nothing" proposition. Instead, it is highly beneficial to provide diversity in the learning experience - lectures, problems, exercises, experiential learning,

\footnotetext{
${ }^{1}$ Based on Apaydin, M. (2008), “Making a Case for the Case Method in Turkey,” Journal of Management Development, Vol. 27 No. 7, pp. 678-692.
} 
problem-based learning, simulations, games, films, field trips or any other teaching technique. The benefits of integrative learning, which includes both cognitive (changes in beliefs) and behavioral (changes in behavior) components, have been pointed out by many scholars (see Inkpen and Crossan (1995) for a summary). The case method develops key skills that would be immediately useful to the graduates starting their management careers: analytical, decision-making, time management, oral and written communication, creative, interpersonal and social skills (Mauffette-Leenders et al., 2005).

Glasser (1986) notes that we remember $10 \%$ of what we read, $20 \%$ of what we hear, $30 \%$ of what we see, $70 \%$ of what we discuss with others, $80 \%$ of what we experience and $95 \%$ of what we teach to others. Small group discussion is especially important in this regard as it allows participants to develop communication skills, foster effective teamwork, develop relationships, build confidence and teach others, thus pushing the knowledge absorption to the maximum.

Case writing may be perceived to be more challenging than simply learning with cases, but it may also be more rewarding, especially in the long term. The process of writing not only a case, but also a teaching note, which includes advice for the instructors how to teach the case, suddenly puts students in the shoes of their teachers - a position they rarely if ever think about. Not only does it provide them with new insights into the class material, it also increases the retention levels (as suggested by Glasser 1986). However, the benefits of case writing extend much further than the time and scope boundaries of a class. A well written case can be published either as a stand-alone paper by any one of the case publishing outlets and academic journals. or can be included in the appropriate academic textbooks, as it will be explained in sections below. The best cases get awards and recognition, and can be featured in students' resumes and CVs as a point of differentiation with respect to other candidates.

The following sections explain specific approaches of case teaching and writing which were implemented by me in Lebanon, Egypt, China and Turkey.

\section{Case teaching in international business (IB) or strategic management courses}

The following approach is based on my 3A framework (Awareness, Analysis and Action) of student learning (Apaydin, 2014). It was developed and implemented in IB and strategic management courses. The case component usually represents between $20 \%$ and $30 \%$ of the course grade and includes a preparatory workshop and 3-5 case assignments to be prepared as Power Point presentations followed by a class discussion. 
Before starting any case work, the students have to attend a 3 hour Case Solving workshop where they learn a systematic approach to decisionmaking and necessary resources to solve cases. This workshop is based on Ivey School of Business methodology described in Mauffette-Leenders et al. (2005).

\section{CPC - case preparation chart}

CPC is a one page map to guide students in individual preparation (see Exhibit 1, adapted from Erskine et al., 2003 ). It starts with defining and prioritizing the issues, followed by data analysis, and selection of alternatives based on specific quantitative and qualitative decision criteria. It ends with a development of implementation plan, specifying missing information and stating assumptions.

CPC has discrete parts that require diligence in execution, and it has an underlying logic that connects all the parts. CPC is graded based on 1) completeness; 2) diligence; 3) data use; 4) logic.

Exhibit 2 presents the framework of case teaching in the strategic management course with identification of the practical skills learned in each module of the course. The detailed explanation is below. The following 3 cases represent the core of the strategic management course.

Starbucks (Ivey Publishing) offers an opportunity to decide on possible growth options: domestic vs. international expansion. After discovering a poor quality Starbucks coffee at a university franchise store, CEO receives an offer from McDonalds. Pressured by investors' expectations of high growth, the CEO has to choose where and how Starbucks can grow: should they focus on the domestic (US) market or go abroad? And if yes, where to? It's a good introductory case given students' familiarity with the brand, which gets them easily engaged with such questions as: what do we buy at Starbucks: coffee or experience? At the same time, the case is rich in data and can be taken to the highest level of analysis and strategic decision-making.

\section{Assignments}

- Prepare CPC individually

- Prepare Power Point Presentation (PPP) as a team to evaluate Starbucks' growth options

- A general class discussion about issues in the case (growth options and the value chain).

Internationalization cases from Egypt (Pearson). Three Egyptian companies decide to expand internationally into 2 countries. El-Sewedy (electrical equipment) is thinking about Italy and Spain, Moderna (textiles) aims at Syria and Jordan and Prime Group (financial services) would like to 
go to Saudi Arabia and Morocco. Three different industries have different structures and success factors and reveal different decision criteria which need to be taken into account when internationalizing. However, each of them can also teach students about rarely studied connection between the subsidiaries themselves. E.g. Spain becoming a distribution hub for Italy and Europe for El-Sewedy, Syria - manufacturing platform for Moderna, and Saudi can supply clients for Moroccan financial market.

\section{Assignments}

- Prepare CPC in pairs (each pair - for 1 case, trying to have equal number of teams for each company)

- Prepare PPP (same as Starbuck) - if too many students in the class each team analyses only 1 country, or 2 teams do 1 country. The idea is not to have more than 6 presentations.

- A general class discussion about issues in the case (8 modes of entry).

Nestle-Rowntree (IMD) offered at the end to consolidate all aspects of the course, including skills learned: I call this case "the Chocolate wars." As a result of poor performance, a UK leading confectionary producer Rowntree becomes an acquisition target. Two Swiss companies (Nestle and Suchard) compete to get this "sweet" deal. This is a very complex case, with a lot of data, different currencies, government involvement and a real-time race to win. It can be used at the end of the course to teach various aspects of global strategy implementation; it also can involve game theory, and negotiations.

\section{Assignments}

- Prepare different analyses of macro, industry and company and present in class (half of the class on behalf of Nestle, another - on behalf of Rowntree, teams of 3 or 4 )

- Prepare and present negotiation strategy, each team focusing on a different issues: 1) what environment needs; 2) what resources can deliver; 3) what management wants

- Conduct live negotiations in class (each team selects one person to represent 1 of 3 members of the management team listed in the case).

\section{Cases' evaluation by students}

The student survey found that students appreciated all the cases almost equally with a slight preference for Nestle-Rowntree because it had an interactive negotiation component and a video. 


\section{Teamwork evaluation}

Team assignment is done based on gender and performance diversity, new teams are created for each case. Therefore, up to a dozen of classmates (depending on the class size) can evaluate a student as a teammate at the end of the course.

\section{Case writing in an IB and strategic management courses}

Case writing was implemented by me in IB and strategic management courses at both graduate and undergraduate levels at the American Universities of Cairo (AUC) and Beirut (AUB). The case assignment was based on the course project suggested in the IB textbook (see \#3 in Exhibit 3) and based on Ivey guidelines in the strategy course.

The project consisted of the following parts:

- General home country (Egypt or Lebanon)

- Business Environment Analysis Report for two countries in which they plan to expand.

- Market Entry Strategy Analysis - target market assessment, sales forecast, entry mode selection and international strategy development.

Case writing was offered as an option that would enable the students to gain additional/better grades than a standard project. The main difference with the project was that the students should have taken a case writing workshop based on Ivey methodology and the write their project content within the frame of a Case and a Teaching Note. The latter was especially challenging given that they suddenly have to "teach" the course instead of learning it.

During three semesters at AUC, 18 cases were written by undergraduate students out of which 5 were published by Ivey Publishing and Pearson (see \#4-5 in Exhibit 3). Four cases were written by MBA students at AUB during a short summer semester 2012 (3 weeks). One of them was published by Ivey Publishing and another by McGraw-Hill. CSRrelated cases dealing with stakeholder management for regional heritage sites and local companies were written by 5 undergraduate teams at AUB for their strategic management course in Spring 2014. They are currently being prepared for publication.

\section{Publication opportunities}

There is a variety of outlets where student cases can be published, which range from main case warehouses (Ivey and ECCH), to academic publishers such as Pearson, McGraw-Hill and Centgage, to specialized case journals. Additionally, cases can be submitted for conferences and 
competitions. More information can be found on MENA Regional Case Initiative website:

http://www.aub.edu.lb/osb/menarcci/activities/Pages/PublishingCases.aspx http://www.aub.edu.lb/osb/menarcci/activities/case_competitions/Pages/case _writing_competitions.aspx

\section{Long-term impact beyond learning about business}

Learning with cases and writing cases provide long-term benefits to the students beyond the scope and the time of a business course:

- Students improve their awareness and understanding of the globally connected world;

- Students develop analytical and quantitative skills which can be applied in other domains;

- Students get prepared for case-based interviews usually administered by consulting and large international companies during recruiting process;

- Students improve their resume/cv with published works;

- Students get connections with local companies and better chances for employment.

Two AUC students (the authors of El Sewedy and Azza Fahmy cases) have offered their reflections about the experience of case learning and writing.

Change is so constant in one's life that it is barely noticeable unless it is a turning point. I took the challenge of writing a case of my own free will, and despite the effort and hours put into it I thought that the challenge would be worth it - and eventually it was. Writing this case and having it published, was a turning point in my life, which made me realize that I have the will power to do anything I can, if I give it my full attention and have the motivation to go through with it. In addition to that it made me realize that having this case published is a competitive edge that makes me compete with peers across the globe.

As promised, Sewedy did proceed with foreign investment after the revolution to sustain profitability.

The company I work for does a lot of business with Pearson, who are currently marketing their "Arab Edition" text books, and every time I see them in a meeting I never fail to brag that I wrote one of these cases and helped in editing a few of them - it does make a difference.

\section{Maha Eshak, AUC Bachelor of Business 2010}

Through my studying at AUC, I solved many cases which helped me in different ways. First cases allowed me to apply different 
management and marketing concepts in real life situations. It also helped me to realize variety of situations that companies confront in real life and how to overcome them. Having a real-life situation, with no specific solution to the issue tackled in the case, broadened my thinking and allowed me to come up with different alternatives to solve this issue. Learning with cases also made me analyze various factors in the company's environment which could affect the decision. Moreover, solving cases provided me with the opportunity to take the decision-maker role in a safe environment where error is acceptable. Reaching different alternatives to solve an issue also helped me to weight these alternatives based on various factors and select the best one. Finally, through cases, I learned that there is no specific right answer. The most important thing is to analyze the situation internally and externally, consider different variable, come up with alternatives, weighing each and choosing the one that fits the situation best.

\section{Hend Mostafa, AUC Master of Business Administration 2010}

(see \#8 in Exhibit 3 for more student feedback).

\section{Creating a full circle system: students - company - instructor - students}

In addition to the benefits to the students described in the previous section, instructors and companies also benefit from case writing:

- Focal companies would receive not only a detailed research on possible countries - targets for expansion, but also an access to the best students willing to extend extra effort.

- Instructors could benefit from better student evaluations (as a result of a more rewarding class), case authorship, collection of material for a qualitative research paper (4 cases is enough according to Yin, 1990) and consulting opportunities with focal companies not to mention the intrinsic satisfaction from seeing the students learn and success. 
Overall, Cases create mutual benefit and develop interconnections of all stakeholders: students, instructors and companies as illustrated in the chart above.

\section{Success stories: "The Life of a Case"”}

I am a case. I now proudly stored at the huge electronic database hosted somewhere together with thousands of other cases from all over the world. But I am special, because I am the first one written by the undergraduate girls from Egypt. I describe El Sewedy, an Egyptian cables company. Who could have thought that young girls would ever be interested in writing about something so technical as cables! One of them approached the owner of the company, Mr. El Sewedy with this idea. Luckily, Mr. El Sewedy, an AUC graduate himself, had a large soul and never missed an opportunity to help the students of his alma mater. In discussions with Mr. El Sewedy, the students decided to explore a possibility for the company to expand into Spain and Italy. Many hours and sleepless nights later, I was born. And then I was groomed a number of times to meet the high standards of Ivey and Pearson Publishing. Meanwhile, Mr. El Sewedy, utterly impressed with girls' work hired one of them as an Assistant to the President.

A few month later, as the Egyptian Revolution erupted together with other upheavals in the Middle East, and El Sewedy business in the region collapsed. Luckily, I was there with all the necessary data for the company to make a quick decision and expand. And so I feel like a savior... Without me, the future of the company wouldn't be so bright, or is it too bold for me to think so?

My adventures didn't stop there. The professor who had the idea to let her students experiment with case writing moved from Cairo to Lebanon. Meanwhile, Pearson published me in the first Arab edition of the Strategy textbook. And guess what, my dear readers? As the professor arrived in Beirut, this very book was adopted by the course coordinator to be used in the capstone course. And so, now Lebanese undergraduate students were learning IB strategy based on a case written by students as themselves. Not only that, one of the authors came from Egypt and talked to her peers about the experience. And of course, I was the center-piece of this talk. How can I not be proud?

\section{Opportunities for the future}

The success of this innovative educational project clearly demonstrates that students are capable and enjoy challenging tasks, given

\footnotetext{
${ }^{2}$ This part was written using "first-person account” style, which can be found in literary works such as Nobel Prize winner Orhan Pamuk’s “My Name is Red”.
} 
that they are provided a clear structure, guidance and can benefit from its outcomes. Possible extensions of this project can be creating a multiplier effect by enabling more experienced students teach new students. This will not only create continuity in learning but also increase the amount of regional learning materials we lack.

\section{References:}

Apaydin, M. (2008), "Making a case for the case method in Turkey," Journal of Management Development, Vol. 27 No. 7, pp. 678-692.

Apaydin, M. (2014), "The 3A Approach: Implementing Practice-Based Interactive Learning Methods in the Middle East," in Leadership Learning for the Future, Information Age Publishing Inc., Ch 6: 87-93.

DeGeus, A.P. (1988), "Planning as learning," Harvard Business Review, Vol. 66 No. 2, pp. 70-74.

Erskine, J.A., Leenders, M.R., and Mauffette-Leenders, L.A. (2003), Teaching with Cases, Third Edition, Ivey Publishing, London, ON.

Glasser, W. (1986), Control Theory in the Classroom, Parennial Library, New York, NY.

Inkpen, A.C. and Crossan, M.M. (1995), "Believing is seeing: joint ventures and organizational learning," Journal of Management Studies, Vol. 32 No.5, pp. 596-618.

Mauffette-Leenders, L.A., Erskine, J.A., and Leenders, M.R. (2005), Learning with Cases, Third Edition, Ivey Publishing, London, ON. 


\section{Exhibit 1}

\section{CASE PREPARATION CHART}

Case Title:

\section{SHORT CYCLE PROCESS}

Name

Who:

What:

Issue(s)

\section{DEVELOPMENT}

Why:

When:

How:

\section{LONG CYCLE PROCESS}

\section{A. Issue(s)}

\section{$\underline{\text { Immediate }}$} 1.

2.

3.

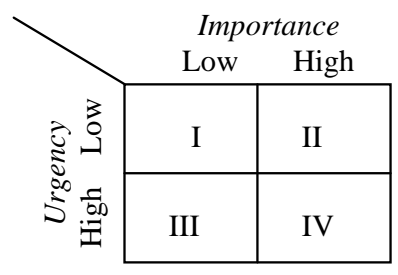

B. Case Data Analysis

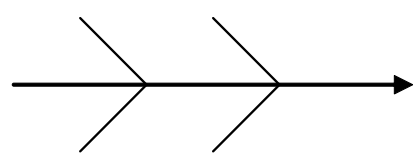

Exhibit 2

Case Assignment: COURSE

II. LONG CYCLE PROCESS

C. Alternative Generation

1. STRUCTURE

2. AND SKILLS

3.

D. Decision Criteria

1.Quntitative....

2.Qualitative....

3.Importance of criteria

E. Alternative Assessment

\begin{tabular}{|l|l|l|l|l|}
\hline Criteria & Cr1 & Cr2 & Cr3 & Weighted \\
\hline Weight & & & & Total \\
\hline Alt 1 & & & & \\
\hline Alt 2 & & & & \\
\hline Alt 3 & & & & \\
\hline
\end{tabular}

F. Preferred Alternative

Predicted Outcome

G. Action \& Implementation Plan

Timing Milestones

Who

What

When

Where

How

$\underline{\text { Missing Information }}$

Assumptions 


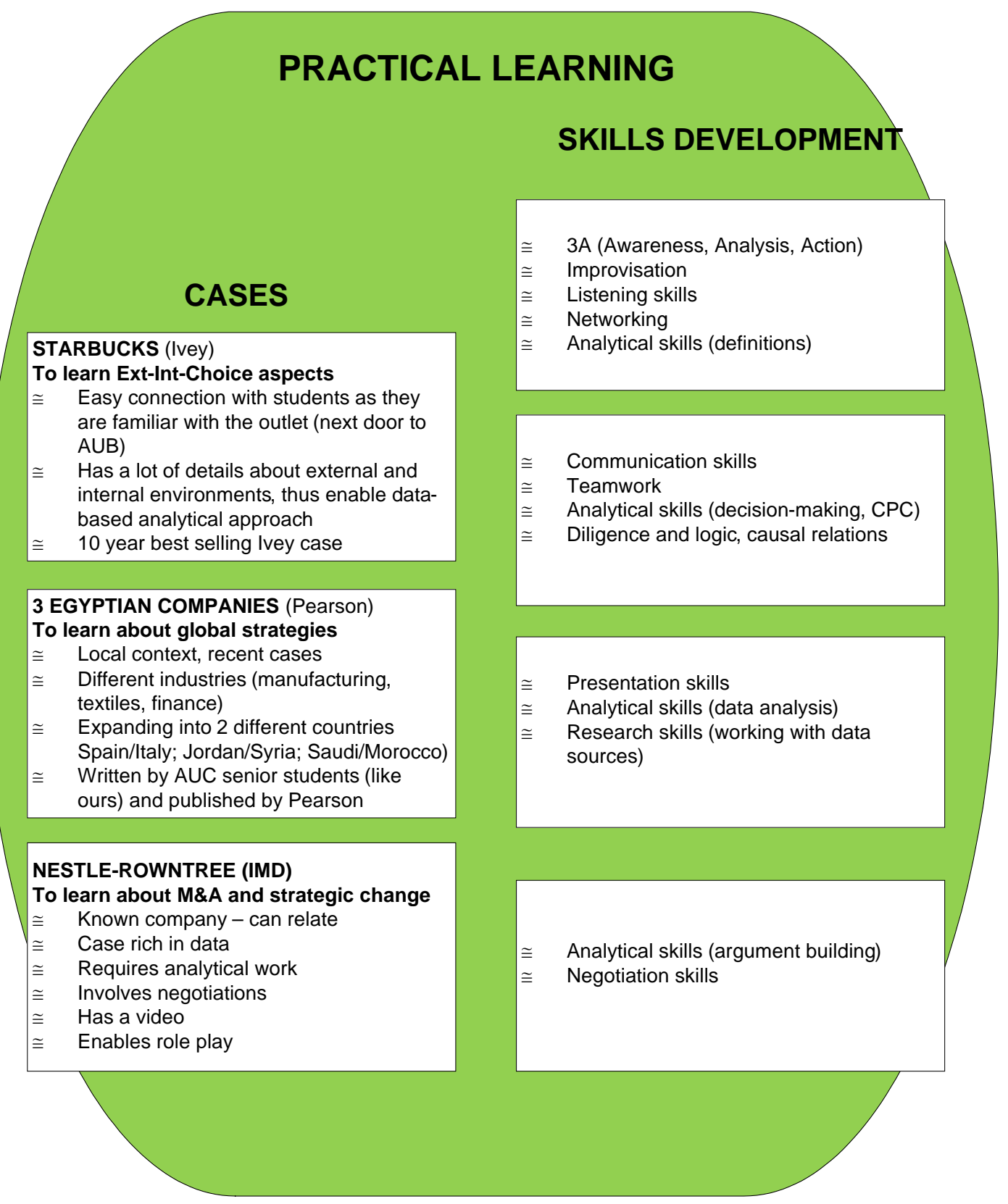




\section{Exhibit 3}

\section{ADDITIONAL RESOURCES}

\section{Ivey Publishing website:}

(https://www.iveycases.com/CaseMateBrowse.aspx?CM=7_ a CaseMate tool which suggests international business cases for instructors' textbook of choice (overall 30 different textbooks are matched with cases).

Middle East and North Africa Regional Case Center Initiative website: (http://www.aub.edu.lb/osb/menarcci/2 - features a comprehensive list of cases from the region available online from all electronic sources

“International Business: Global Edition" $14^{\text {th }}$ edition (2013) by Daniels, Radebaugh \& Sullivan (Pearson) features a course project which can be converted into case-writing.

(http://catalogue.pearsoned.co.uk/educator/product/International-BusinessGlobal-Edition/9780273766957.page)

"Strategic Management: Concepts and Cases" (Arab World Editions) (2011) by Ali, Al-Aali, David, Ali \& Al Aali (Pearson) features 3 cases written by AUC students

(http://catalogue.pearsoned.co.uk/educator/product/Strategic-ManagementConcepts-and-Cases-Arab-World-Editions-with-MymanagementLab-AccessCode-Card/9781408289631.page)

Ivey Publishing: other IB cases written by AUC/AUB students

"El Mawardy Jewelry":

https://www.iveycases.com/ProductView.aspx?id=51412

"Orascom telecom":

https://www.iveycases.com/ProductView.aspx?id=51343

"Jabwood International":

https://www.iveycases.com/ProductView.aspx?id=56454

The American University of Cairo - School of Business

(http://www.aucegypt.edu/Business/Pages/default.aspx)

The American University of Beirut - Olayan School of Business

(http://www.aub.edu.lb/osb/)

Student feedback about the IB course with case writing component

(http://www1.aucegypt.edu/faculty/marina/alumniNet.html\#student_INTB30

1) 